\title{
A 10-day vacancy period after cleaning and disinfection has no effect on the bacterial load in pig nursery units
}

\author{
K. Luyckx', S. Millet ${ }^{1}$, S. Van Weyenberg' ${ }^{1}$, L. Herman¹, M. Heyndrickx ${ }^{1,2}$, J. Dewulf ${ }^{3}$ and K. De Reu ${ }^{1 *}$
}

\begin{abstract}
Background: Biosecurity measures such as cleaning, disinfection and a vacancy period between production cycles on pig farms are essential to prevent disease outbreaks. No studies have tested the effect of a longer vacancy period on bacterial load in nursery units.

Methods: The present study evaluated the effect of a 10-day vacancy period in pig nursery units on total aerobic flora, Enterococcus spp., Escherichia coli, faecal coliforms and methicillin resistant Staphylococcus aureus (MRSA). Three vacancy periods of 10 days were monitored, each time applied in 3 units. The microbiological load was measured before disinfection and at 1, 4, 7 and 10 days after disinfection.

Results: No significant decrease or increase in E. coli, faecal coliforms, MRSA and Enterococcus spp. was noticed. Total aerobic flora counts were the lowest on day 4 after disinfection (i.e. $4.07 \log$ CFU/625 cm $\left.{ }^{2}\right)(P<0.05)$, but the difference with other sampling moments was limited (i.e. $0.6 \log \mathrm{CFU} / 625 \mathrm{~cm}^{2}$ ) and therefore negligible. Furthermore, this observation on day 4 was not confirmed for the other microbiological parameters. After disinfection, drinking nipples were still mostly contaminated with total aerobic flora (i.e. $5.32 \log$ CFU/625 $\mathrm{cm}^{2}$ ) and Enterococcus spp. (i.e. $95 \%$ of the samples were positive) $(P<0.01)$; the feeding troughs were the cleanest location (total aerobic flora: $3.53 \log$ CFU/625 $\mathrm{cm}^{2}$ and Enterococcus spp.: $50 \%$ positive samples) $(P<0.01)$.

Conclusions: This study indicates that prolonging the vacancy period in nursery units to 10 days after disinfection with no extra biosecurity measures has no impact on the environmental load of total aerobic flora, E. coli, faecal coliforms, MRSA and Enterococcus spp..
\end{abstract}

Keywords: Nursery pigs, Between batch vacancy, Cleaning and disinfection, Bacterial load

\section{Background}

Weaned piglets are subjected to many environmental, behavioural and dietary stresses. Moreover, the intestinal gut flora is still precarious, which makes them highly susceptible to enteric diseases [1]. Disease outbreaks in animal houses can lead to animal mortality and higher condemnation rates at slaughterhouses. The resulting economic damage can be severe [2] together with preventive measures (e.g. quarantine in case of epidemics) and even destruction of farm animals [3]. In addition, foodborne zoonotic diseases are a significant and widespread global public health threat.

\footnotetext{
* Correspondence: koen.dereu@ilvo.vlaanderen.be

${ }^{1}$ Institute for Agricultural and Fisheries Research (ILVO), Merelbeke, Belgium Full list of author information is available at the end of the article
}

In nursery units, diarrhoea is one of the most important causes of economic losses in the pig industry. Post-weaning diarrhoea is multifactorial but the proliferation of pathogenic Escherichia coli strains throughout the intestinal tract of piglets after weaning has been shown to play a significant role $[4,5]$. Another important pathogen for the pig industry is Salmonella. In 2011, most of the reported food-borne outbreaks (69 553 human cases) in the European Union were associated with food originating from animals. Salmonella was the most frequently detected causative agent (26.6\% of outbreaks) [6].

Methicillin resistant Staphylococcus aureus sequence type 398 (MRSA ST398) is an emerging opportunistic pathogen among farm animals, especially pigs [7-9]. Epidemiological studies have shown that they not only 
colonise pigs, but can also be transmitted to persons with direct livestock exposure. Moreover, it is indicated that MRSA ST6398 represents an increasing cause of infections in humans [10].

It is of great importance to prevent disease outbreaks through biosecurity measures rather than cure them [3]. Biosecurity includes all measures that prevent pathogens from entering a herd (external biosecurity) as well as reducing the spread of pathogens within the herd (internal biosecurity) [11]. Between production cycles, internal biosecurity measures such as cleaning, disinfection and a vacancy period are applied. Every biosecurity measure can influence the degree of infection pressure before new animals arrive.

Luyckx et al. [12] showed that a cleaning step in broiler houses caused a reduction of total aerobic flora by $2 \log C F U / 625 \mathrm{~cm}^{2}$ and that a disinfection step caused a further reduction of $1.5 \log$ CFU. In piglet nursery units, the importance of a prolonged vacancy period is unknown. The aim of the present study was to assess the evolution of the bacterial load of total aerobic flora, Enterococcus spp., E. coli, faecal coliforms and MRSA during a 10-day vacancy period in piglet nursery units. Enterococcus spp. and faecal coliforms are suggested to be adequate hygiene-indicator organisms for faecal contamination of surfaces. In addition, E. coli have been shown to be suitable index organisms for monitoring the possible presence of Salmonella [13-15].

\section{Results}

Before disinfection, the mean enumeration of total aerobic flora was $5.64 \log \mathrm{CFU} / 625 \mathrm{~cm}^{2}$ (Fig. 1a). The proportion of positive samples for E. coli, faecal coliforms and MRSA (after enrichment) and Enterococcus spp. was 49, 65 and 16 \% (Fig. 2a) and 95 \% (Fig. 3a), respectively.
On day 1 after disinfection, mean enumeration of total aerobic flora was significantly reduced to $4.44 \log \mathrm{CFU} /$ $625 \mathrm{~cm}^{2}(P<0.01)$ (Fig. 1a). Of the 135 samples taken on day 1, 13, 23 and $7 \%$ were positive for $E$. coli, faecal coliforms and MRSA detection, respectively (Fig. 2a). In addition, $69 \%$ of the samples gave countable results for Enterococcus spp. (Fig. 3a). The proportion of positive samples for E. coli, faecal coliforms and Enterococcus spp. was significantly lower compared to the proportions found before disinfection $(P<0.01)$.

Three days later (day 4), total aerobic flora were significantly reduced to $4.07 \mathrm{log} \mathrm{CFU} / \mathrm{cm}^{2}(P<0.05)$. Only $7 \%$ of the samples were positive for $E$. coli, but the number of positive samples found for faecal coliforms and MRSA were higher (25 and $14 \%$, respectively). Countable results for Enterococcus spp. also increased to $77 \%$.

On day 7 after disinfection, mean enumeration of total aerobic flora was $4.24 \log \mathrm{CFU} / 625 \mathrm{~cm}^{2}$. Of all samples, 15,29 and $13 \%$ were positive for E. coli, faecal coliforms and MRSA detection, respectively and comparable to day $1,70 \%$ of the samples gave countable results for Enterococcus spp..

On day 10, total aerobic flora increased further to 4.67 $\log \mathrm{CFU} / 625 \mathrm{~cm}^{2}$, which was $0.6 \log$ CFU more than 4 days after disinfection $(P<0.01)$, but not significantly different from day 1. Proportion of positive samples for E. coli, faecal coliforms and MRSA were 12, 24 and $8 \%$, respectively. In addition, $79 \%$ of the samples were countable for Enterococcus spp..

Overall, no significant differences were noticed between sampling moments after disinfection for E. coli, faecal coliforms, MRSA and Enterococcus spp..

During the entire 10-day vacancy period, the overall contamination level (total aerobic flora) was the highest

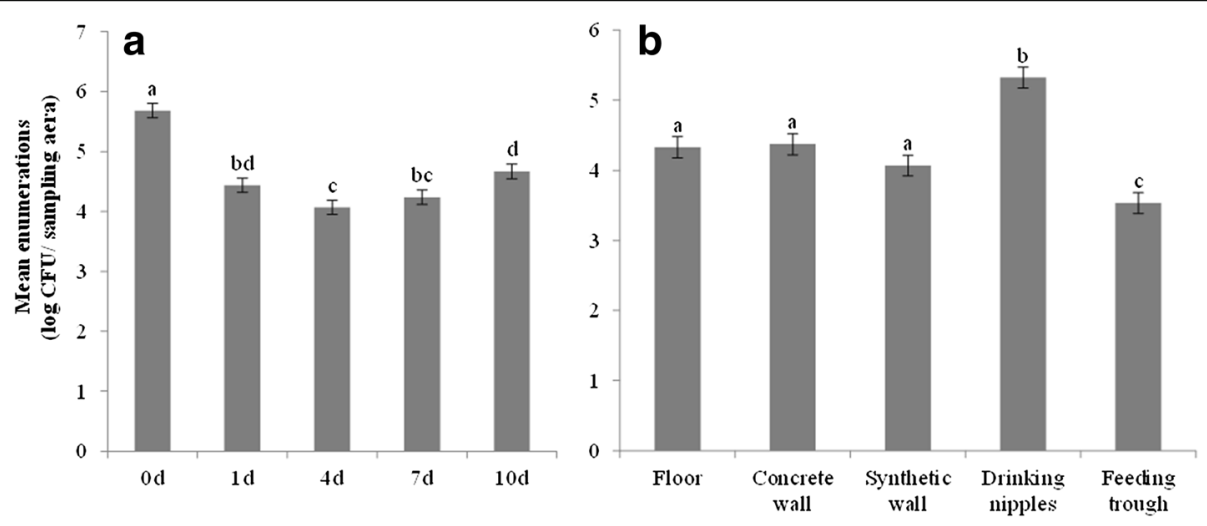

Fig. 1 Mean enumeration of total aerobic flora with standard errors. Mean enumerations are given for each sampling moment (a) and location after disinfection (b). Samples ( $n=135$ ) were taken before disinfection (0d) and 1 day (1d), 4 days (4d), 7 days (7d) and 10 days (10d) after disinfection. Samples $(n=108)$ were taken from each location. Significant differences between sampling moments/ locations are indicated by different letters above bars 

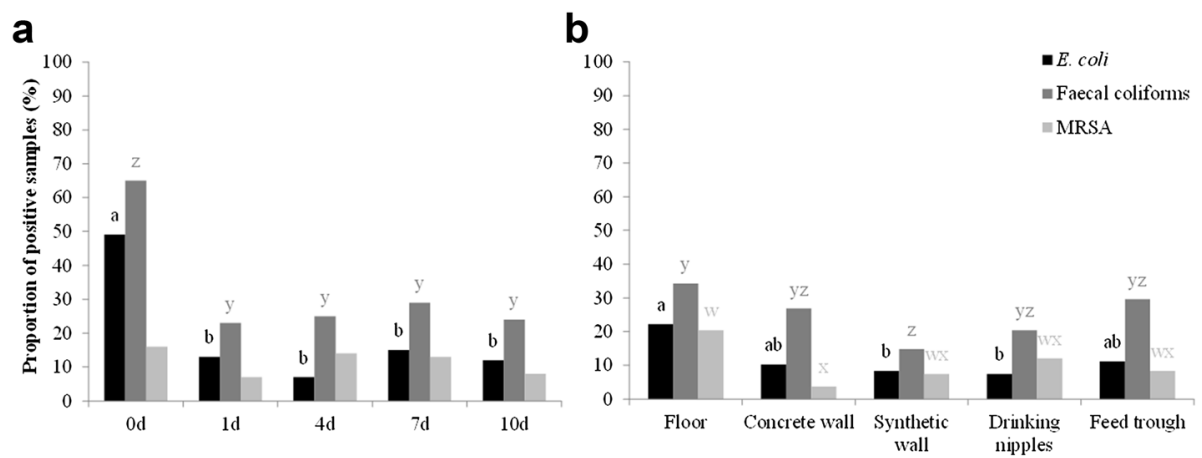

Fig. 2 Proportion of positive samples given for detection of E. coli, faecal coliforms and MRSA, respectively. Proportions are given for each sampling moment (a) and location after disinfection (b), in percentage. Samples $(n=135)$ were taken before disinfection (0d) and 1 day $(1 \mathrm{~d})$, 4 days (4d), 7 days (7d) and 10 days (10d) after disinfection. Samples $(n=108)$ were taken from each location. Significant differences between sampling moments/ locations per bacteriological parameter are indicated by different letters above bars

for drinking nipples (i.e. $\left.5.32 \log \mathrm{CFU} / 625 \mathrm{~cm}^{2}\right)(P<0.01)$ and the lowest for feeding troughs (i.e. $3.53 \log \mathrm{CFU} /$ $\left.625 \mathrm{~cm}^{2}\right)(P<0.01)$ (Fig. 1b). Results of Enterococcus spp. confirmed these observations $(P<0.01)$ and also showed that the floors were still highly contaminated (i.e. still $84 \%$ of the samples were positive) $(P<0.01)$ (Fig. $3 \mathrm{~b})$. Results for E. coli, faecal coliforms and MRSA did not indicate the most critical locations after cleaning and disinfection (C\&D) (Fig. 2b).

During the vacancy period, mean temperature ranged from $15^{\circ} \mathrm{C}$ to $16^{\circ} \mathrm{C}$ and relative humidity (RH) from 57 to $67 \%$ (Fig. 4). These two parameters did not have a significant effect on the different bacteriological parameters.

\section{Discussion}

Biosecurity measures, such as cleaning and disinfection $(C \& D)$ and a prolonged vacancy period of the animal houses are an essential part of the hygiene management on the farm to prevent disease outbreaks. The effect of a vacancy period of 10 days after disinfection on several bacteriological parameters was examined during this study.

Disinfection reduced the total aerobic flora by $1.2 \log$ CFU/ sampling surface. During the following 10 day vacancy, only a small reduction was observed on day 4 , though this seemed microbiological negligible (maximum difference of $0.6 \log \mathrm{CFU} / 625 \mathrm{~cm}^{2}$ ). One possible explanation for the observed small fluctuations and the decline of total aerobic flora on day 4 is that some bacteria can survive stressful conditions by entering a viable but nonculturable state [14]. These nonculturable bacteria were not enumerated nor detected by the methods used in this study. Another possible explanation is that residual flora could proliferate again after disinfection, due to lack of niche and nutrient competition with other bacteria. These residual bacteria could have survived the disinfection step
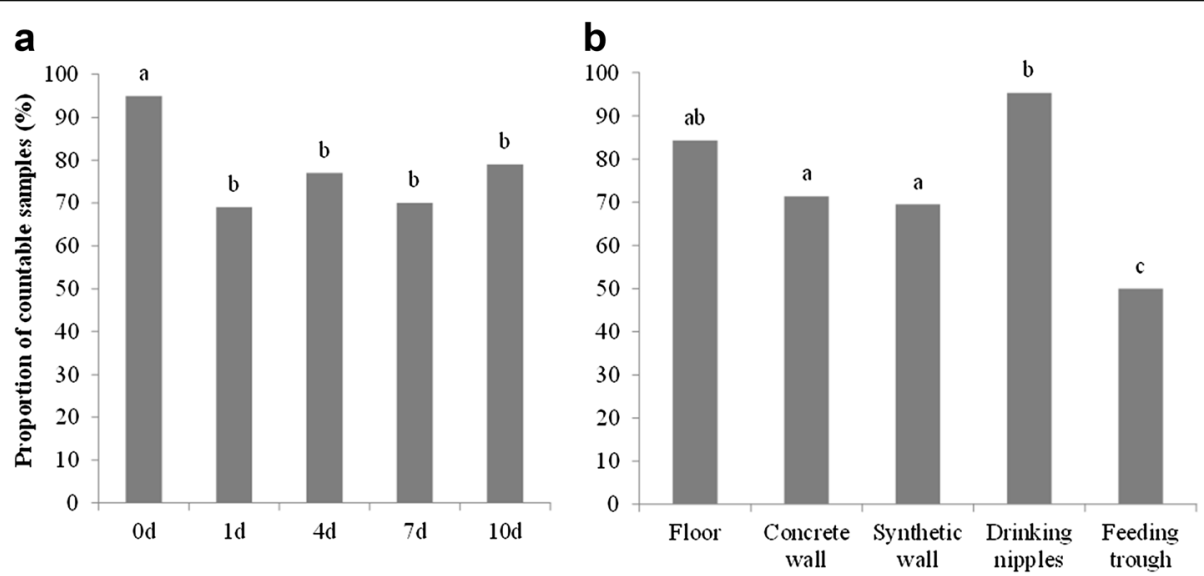

Fig. 3 Proportion of countable samples given in percentage for Enterococcus spp.. Proportions are given for each sampling moment (a) and location after disinfection (b). Samples ( $n=135)$ were taken before disinfection (0d) and 1 day (1d), 4 days ( 4 d), 7 days (7d) and 10 days (10d) after disinfection. Samples $(n=108)$ were taken from each location. Significant differences between sampling moments are indicated by different letters above bars 


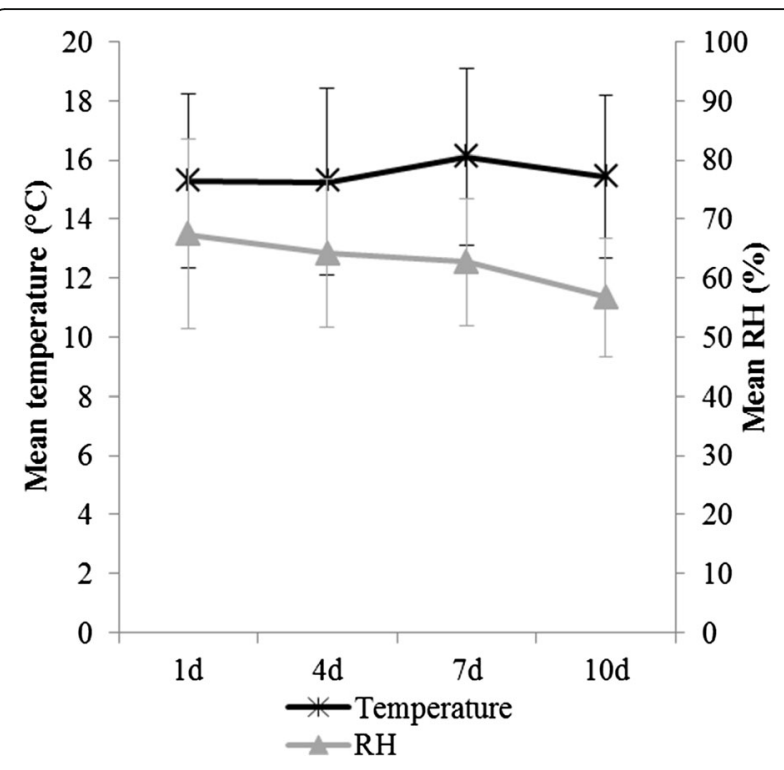

Fig. 4 Mean temperature $\left({ }^{\circ} \mathrm{C}\right)$ and relative humidity $(\mathrm{RH}, \%)$ with standard deviations given per sampling moment. Sampling moments: day 1 (1d), 4 (4d), 7 (7d), 10 (10d) after disinfection

by the presence of a resistance mechanism [16-19] or by detrimental factors present during disinfection, such as residual organic material.

Moreover, a longer vacancy period can even have a negative effect, not only financially because of a lower number of production cycles (i.e. lower income) but also bacteriologically. For example, recontamination could occur by vectors such as vermin and rodents in case of biosecurity breaches [20-22], especially when other compartments in the same building are still filled with animals or if residual organic material (e.g. faeces and feed) is present after C\&D. Flies may be reservoirs and vectors of several bacteria such as Salmonella [20, 23, 24], E. coli O157:H7 [25], Staphylococcus aureus [26] and Streptococcus suis type 2 [27]. Wild rodents can also carry pathogens such as Salmonella, Campylobacter, Yersinia and MRSA ST398 [28-31]. As biosecurity measures are very well implemented on the pilot farm, it can be assumed that on other farms, the bacteriological load and infection pressure may even increase during vacancy.

Some bacteria can survive for long periods under various conditions in the environment, such as Salmonella, Staphylococcus aureus (including MRSA) and Enterococcus spp. [32]. The results from the present study indicate that a prolonged vacancy period without extra biosecurity measures creates no reduction in these bacteria. Extra biosecurity measures such as specific pathogen control programs and pest control during the vacancy period could therefore be beneficial.

Finally, the contamination levels of several locations were analysed during the vacancy period. Drinking nipples were still mostly contaminated with total aerobic flora and Enterococcus spp.. Luyckx et al. [33] showed that drinking cups are critical locations for $C \& D$ in broiler houses. Drinking water from these contaminated sources could be a possible cause for disease in animals. Therefore extra attention should be given to these locations during $\mathrm{C} \& \mathrm{D}$ and during the vacancy period. In addition, also disinfection of drinking lines is recommended as they can be contaminated with biofilms, including pathogenic bacteria [34]. As this study is carried out on an experimental farm, also other locations can be identified as critical locations for $C \& D$, due to their different specific structural design or composition compared to the studied farm.

\section{Conclusion}

This study indicates that a vacancy period up to 10 days after cleaning and disinfection with no extra biosecurity measures has no beneficial effect on the bacterial load of total aerobic flora, E. coli, faecal coliforms, MRSA and Enterococcus spp. in piglet nursery units.

\section{Methods}

\section{Sampling plan}

This study was carried out in 6 identical nursery units (A1 to A3 and B1 to B3) on the experimental pig farm at the Institute for Agricultural and Fisheries Research (ILVO, Merelbeke, Belgium). Each unit consists of 8 pens of $1.8 \mathrm{~m}^{2}$. Piglets were moved to these units immediately after weaning ( 4 weeks of age) and stayed there for 6 weeks. Each pen housed 6 piglets. Pen flooring was a synthetic grid, under which a board slopes towards a centrally-located slurry pit. Units A1 to A3 were monitored during 2 successive vacancy periods in February and April 2015 and units B1 to B3 during 1 vacancy period in March 2015. After pig removal, units were soaked with water. The day after, units were cleaned with hot water $\left(80{ }^{\circ} \mathrm{C}\right)$, then disinfected with $1 \%(\mathrm{v} / \mathrm{v})$ MS Megades (Schippers, Bladel, The Netherlands) on the same day. The disinfection product consists of glutaraldehyde and quaternary ammonium compounds. After cleaning and disinfection, the pen remained vacant for 10 days. During this vacancy period, temperature and relative humidity $(\mathrm{RH})$ were monitored hourly using thermo-hygrometers (Ilog EI-HS-D-32-L, ESCORT data logging systems). Three random pens per unit were sampled before disinfection and at 1, 4, 7 and 10 days after disinfection. Per sampling moment, 135 samples were taken, for a total of 675 samples.

\section{Sample processing}

Sponge swab samples (3 M, SSL100, St. Paul, MN, USA), pre-moistened with $10 \mathrm{~mL}$ Ringers solution (Oxoid, BR0052G, Basingstroke, Hampshire, England), 
were taken at 5 locations per pen: floor, concrete wall, synthetic wall, drinking nipples and feeding trough. Sampling of 3 pens per unit resulted in triplicates per type of location or 15 swab samples per unit at each time point. To neutralise the residual action of the disinfectants on the microbiological growth, $10 \mathrm{~mL}$ Dey Engley neutralising broth (Sigma Aldrich, Fluka, D3435, St-Louis, MO, USA) was used to pre-moisten the sponge swab samples that were used on day 1 after disinfection. A surface of $625 \mathrm{~cm}^{2}$ (A4 paper format) was sampled whenever possible. Because the surface of the drinking nipples was smaller than $625 \mathrm{~cm}^{2}, 2$ drinking nipples per pen were sampled. Samples were transported to the lab under refrigeration and were processed immediately. For all measured pathogens, selected relevant parameters and enumeration or detection techniques were based on Luyckx et al. [12]. Swab samples were first diluted with $30 \mathrm{~mL}$ of Buffered Peptone Water (BPW, Oxoid, CM0509) and then homogenised by placing them in a Masticator (IUL instruments, S.A., Barcelona, Spain). Prior to plating, swab samples were further diluted in dilution series in saline peptone water (Bio Trading, K110B009AA, Mijdrecht, The Netherlands) to produce countable results on the selected agar media: Plate Count Agar (Oxoid, CM0325) for total aerobic flora and Slanetz and Bartley (Oxoid, CM0377) for Enterococcus spp. (lower enumeration limit $30 \mathrm{CFU} / 625 \mathrm{~cm}^{2}$ ). Plate Count Agar and Slanetz and Bartley plates were incubated at 30 and $37^{\circ} \mathrm{C}$ during 72 and $48 \mathrm{~h}$, respectively. A $10 \mathrm{~mL}$ BPW fraction was also transferred to a Stomacher bag and mixed with $10 \mathrm{~mL}$ double concentrated Mueller Hinton Broth (Oxoid, CM0405) and $13 \%(\mathrm{w} / \mathrm{v})$ sodium chloride (Merck, 1.06404.500, Darmstadt, Germany). After overnight incubation of this solution at $37^{\circ} \mathrm{C}, 100 \mu \mathrm{l}$ was plated on chromID ${ }^{\circ}$ MRSA SMART (MRSM, bioMérieux, Marcy l'Etoile, France) for the detection of MRSA. ChromID ${ }^{\circ}$ MRSA SMART were incubated at $37{ }^{\circ} \mathrm{C}$ for $24-$ $48 \mathrm{~h}$. The remaining BPW fraction (original sample) was also incubated overnight at $37{ }^{\circ} \mathrm{C}$ for additional analyses: for detection of $E$. coli and faecal coliforms, $10 \mu \mathrm{l}$ of the enrichment broth was plated onto Rapid E. coli medium (Biorad, 356-4024, Marnes-la-Coquettes, France) and incubated for $24 \mathrm{~h}$ at $44{ }^{\circ} \mathrm{C}$.

\section{Statistical analysis}

The distribution of the log-transformed enumerations of total aerobic flora and Enterococcus spp. was analysed via graphs (Q-Q plot and histogram). The log-transformed enumerations of total aerobic flora followed a normal distribution. A linear regression model was conducted to evaluate the effect of a vacancy period and location on the log-transformed total aerobic flora enumerations (dependent variable). To assess the effect of predictor variables (vacancy period and location) on the non-normally distributed outcome variables, variables describing the enumeration and detection of the different bacteria (Enterococcus spp., E. coli, faecal coliforms and MRSA) were transformed into binary variables (absent or below the detection limit $=0$, present $=1$ ). Subsequently a logistic regression analysis was carried out. Temperature and RH were added as covariates in both models. Variable "unit" was included as a random effect in both models to correct for measurements within one unit.

Post-hoc comparison was performed with a TukeyKramer test. $P$-values $\leq 0.05$ were considered as significant. All statistical analyses were carried out using Statistical Analysis System software $\left(\mathrm{SAS}^{\oplus}\right.$, version 9.4, SAS Institute Inc., Cary, NC, USA).

\section{Abbreviations}

0d: Day before disinfection; 10d: 10 days after disinfection; 1d: 1 day after disinfection; 4d: 4 days after disinfection; $7 \mathrm{~d}$ : 7 days after disinfection; BPW: Buffered peptone water; C\&D: Cleaning and disinfection; CFU: Colony forming units; E. coli: Escherichia coli; MRSA: Methicillin resistant

Staphylococcus aureus; $\mathrm{RH}$ : Relative humidity

\section{Acknowledgements}

Many thanks go to Kristof Dierkens and Eline Dumoleijn for their practical support. We also thank Miriam Levenson for English-language editing of this manuscript.

\section{Funding}

This research is funded by the Belgian Federal Public Service for Health, Food Chain Safety and Environment (RT 11/8 Cleandesopt).

\section{Availability of data and materials}

The datasets supporting the conclusions of this article are included within the article.

\section{Authors' contributions}

$\mathrm{KL}$ was involved in the sample collection, laboratory analyses, analyses, interpretation of the data and drafting the manuscript. JD, SM and KD coordinated the study. SWW evaluated the statistical analyses. KL, SM, SWW, $\mathrm{LH}, \mathrm{MH}, \mathrm{JD}$ and $\mathrm{KD}$ contributed to development and writing of the paper. All authors read and approved the final manuscript.

\section{Competing interest}

The authors declare that they have no competing interests.

\section{Consent for publication}

Not applicable.

\section{Ethics approval and consent to participate} Not applicable.

\section{Author details}

${ }^{1}$ Institute for Agricultural and Fisheries Research (ILVO), Merelbeke, Belgium ${ }^{2}$ Department of Pathology, Bacteriology and Poultry Diseases, Ghent University, Faculty of Veterinary Medicine, Merelbeke, Belgium. ${ }^{3}$ Veterinary Epidemiology Unit, Department of Reproduction, Obstetrics and Herd Health, Faculty of Veterinary Medicine, Ghent University, Merelbeke, Belgium.

Received: 9 January 2016 Accepted: 30 September 2016

Published online: 19 October 2016

\section{References}

1. Hopwood DE, Hampson DJ. Interactions between the intestinal microflora, diet and diarrhoea, and their influences on piglet health in the immediate post-weaning period. In: Pluske JR, Dividich J, Verstegen MWA, editors. Weaning the pig: concept and consequences. Wageningen: Wageningen Academic Publishers; 2003. 
2. Jung A, Rautenschlein S. Comprehensive report of an Enterococcus cecorum infection in a broiler flock in Northern Germany. BMC Vet Res. 2014;10:1. Available from: http://www.biomedcentral.com/1746-6148/10/311.

3. Gelaude P, Schlepers M, Verlinden M, Laanen M, Dewulf J. Biocheck. UGent: a quantitative tool to measure biosecurity at broiler farms and the relationship with technical performances and antimicrobial use. Poult Sci. 2014;93:2740-51. [cited 2015 Mar 13]. Available from: https://biblio.ugent. be/record/5790918.

4. Hampson DJ. Postweining Escherichia coli diarrhoea in pigs in Escherichia coli. In: Hampson DJ, editor. Domestic animals and humans. Wallingford: CAB International; 1994.

5. Richards WPC, Fraser CM. Coliform enteritis of weaned pigs. A description of the disease and its association with haemolytic Escherichia coli. Cornell Vet. 1961;51:245-57.

6. European Food Safety Authority (EFSA). The European Union summary report on trens and sources of zoonoses, zoonotic agents and food-borne outbreaks in 2011. EFSA J. 2014;12:3547.

7. Vanderhaeghen W, Hermans K, Haesebrouck F, Butaye P. Methicillin-resistant Staphylococcus aureus (MRSA) in food production animals. Epidemiol Infect. 2010;138:606-25. 2010/02/04 ed. Available from: http://journals.cambridge. org/download.php?file=\%2FHYG\%2FHYG138_05\%2FS0950268809991567a. pdf\&code=16772c8a999fa94b13924f0d065b8fde.

8. Weese JS. Methicillin-resistant Staphylococcus aureus in animals. ILAR J. 2010; 51:233-44. 2010/12/07 ed. Available from: http://ilarjournal.oxfordjournals. org/content/51/3/233.full.pdf.

9. Smith TC, Pearson N. The emergence of Staphylococcus aureus ST398. Vector Borne Zoonotic Dis. 2011;11:327-39.

10. Köck R, Schaumburg F, Mellmann A, Köksal M, Jurke A, Becker K, et al. Livestockassociated methicillin-resistant Staphylococcus aureus (MRSA) as causes of human infection and colonization in Germany. PLoS One. 2013:8:e55040.

11. Sarrazin S, Cay AB, Laureyns J, Dewulf J. A survey on biosecurity and management practices in selected Belgian cattle farms. Prev Vet Med. 2014; 117:129-39. [cited 2015 Apr 28]. Available from: http://www.ncbi.nlm.nih. gov/pubmed/25156945.

12. Luyckx K, Dewulf J, Van Weyenberg S, Herman L, Zoons J, Vervaet E, et al. Comparison of sampling procedures and microbiological and nonmicrobiological parameters to evaluate cleaning and disinfection in broile houses. Poult Sci. 2015;94:740-9. 2015/02/15 ed. Available from: http://ps. oxfordjournals.org/content/94/4/740.full.pdf.

13. Dewaele I, Ducatelle R, Herman L, Heyndrickx M, De Reu K. Sensitivity to disinfection of bacterial indicator organisms for monitoring the Salmonella Enteritidis status of layer farms after cleaning and disinfection. Poult Sci. 2011;90:1185-90.

14. Winfield MD, Groisman EA. Role of nonhost environments in the lifestyles of Salmonella and Escherichia coli. Appl Environ Microbiol. 2003;69:3687-94. Available from: http://aem.asm.org/content/67/7/3687.full.

15. Gradel KO, Jørgensen JC, Andersen JS, Corry JEL. Monitoring the efficacy of steam and formaldehyde treatment of naturally Salmonella-infected layer houses. J Appl Microbiol. 2004;96:613-22.

16. Russell AD. Mechanisms of bacterial resistance to antibiotics and biocides. Prog Med Chem. 1998:35:133-97. 2000/05/05 ed.

17. Mateu $E$, Martin M. Why is anti-microbial resistance a veterinary problem as well? J Vet Med B Infect Dis Vet Public Health. 2001;48:569-81. 2001/11/16 ed. Available from: http://onlinelibrary.wiley.com/store/10.1111/j.1439-0450. 2001.00475.x/asset/j.1439-0450.2001.00475.x.pdf?v=1\&t=i8u4961r\&s= 2d0e01a74bfb566ed1ff925d23959c110a903188.

18. Soumet C, Fourreau E, Legrandois P, Maris P. Resistance to phenicol compounds following adaptation to quaternary ammonium compounds in Escherichia coli. Vet Microbiol. 2012;14:147-52.

19. Callens BF, Haesebrouck F, Maes D, Butaye P, Dewulf J, Boyen F. Clinical resistance and decreased susceptibility in Streptococcus suis isolates from clinically healthy fattening pigs. Microb Drug Resist. 2013;19:146-51. [cited 2015 Jun 10]. Available from: http://www.ncbi.nlm.nih.gov/pubmed/23249177.

20. Dewaele I, Van Meirhaeghe H, Rasschaert G, Vanrobaeys M, De Graef E, Herman L, et al. Persistent Salmonella Enteritidis environmental contamination on layer farms in the context of an implemented national control program with obligatory vaccination. Poult Sci. 2012;91:282-91.

21. Hald B, Skovgård H, Bang DD, Pedersen K, Dybdahl J, Jespersen JB, et al. Flies and Campylobacter infection of broiler flocks. Emerg Infect Dis. 2004;10: 1490-2. [cited 2015 Apr 29]. Available from: http://www.pubmedcentral.nih. gov/articlerender.fcgi?artid=3320412\&tool=pmcentrez\&rendertype=abstract.
22. Meerburg BG, Vermeer HM, Kijlstra A. Controlling risks of pathogen transmission by flies on organic pig farms: a review. Outlook Agric. 2007;36: 193-7. IP Publishing Ltd; 2007 [cited 2015 Apr 29]. Available from: http://www. ingentaconnect.com/content/ip/ooa/2007/00000036/00000003/art00006.

23. Holt PS, Geden CJ, Moore RW, Gast RK. Isolation of Salmonella enterica serovar Enteritidis from houseflies (Musca domestica) found in rooms containing Salmonella serovar Enteritidis-challenged hens. Appl Environ Microbiol. 2007;73:6030-5. [cited 2015 Apr 29];73:6030-5. Available from: http://www.pubmedcentral.nih.gov/articlerender.fcgi?artid=2075029\&tool= pmcentrez\&rendertype=abstract.

24. Olsen AR, Hammack TS. Isolation of Salmonella spp. from the housefly, Musca domestica L., and the dump fly, Hydrotaea aenescens (Wiedemann) (Diptera: Muscidae), at caged-layer houses. J Food Prot. 2000;63:958-60. [cited 2015 Apr 29]. Available from: http://www.ncbi.nlm.nih.gov/pubmed/10914668.

25. Szalanski AL, Owens CB, McKay T, Steelman CD. Detection of Campylobacter and Escherichia coli 0157:H7 from filth flies by polymerase chain reaction. Med Vet Entomol. 2004;18:241-6. [cited 2015 Apr 24]. Available from: http:// www.ncbi.nlm.nih.gov/pubmed/15347391.

26. Owens WE, Oliver SP, Gillespie BE, Ray CH, Nickerson SC. Role of horn flies (Haematobia irritans) in Staphylococcus aureus-induced mastitis in dairy heifers. Am J Vet Res. 1998;59:1122-4. [cited 2015 Apr 29]. Available from: http://europepmc.org/abstract/med/9736388.

27. Marois C, Le Devendec L, Gottschalk M, Kobisch M. Detection and molecular typing of Streptococcus suisin tonsils from live pigs in France. Can J Vet Res. 2007;71:14-22. [cited 2015 Oct 2]. Available from: /pmc/articles/ PMC1635993/2report=abstract.

28. Backhans A, Fellström C. Rodents on pig and chicken farms - a potential threat to human and animal health. Infect Ecol Epidemiol. 2012 [cited 2015 Apr 29];2. Available from: http://www.pubmedcentral.nih.gov/articlerender. fcgi?artid=3426328\&tool=pmcentrez\&rendertype=abstract

29. Pletinckx LJ, Dewulf J, De Bleecker Y, Rasschaert G, Goddeeris BM, De Man I. Effect of a disinfection strategy on the methicillin-resistant Staphylococcus aureus CC398 prevalence of sows, their piglets and the barn environment. J Appl Microbiol. 2013;114:1634-41. 2013/04/05 ed. Available from: http:// onlinelibrary.wiley.com/store/10.1111/jam.12201/asset/jam12201.pdf?v=1\&t= i8u49xuk\&s=d66db3229e37a9c36dabf54f1cdf3da2d7b397e8.

30. van de Giessen AW, van Santen-Verheuvel MG, Hengeveld PD, Bosch T, Broens EM, Reusken CBEM. Occurrence of methicillin-resistant Staphylococcus aureus in rats living on pig farms. Prev Vet Med. 2009;91: 270-3. [cited 2015 May 8]. Available from: http://www.ncbi.nlm.nih.gov/ pubmed/19523703.

31. Dewaele I, Rasschaert G, Wildemauwe C, Van Meirhaeghe H, Vanrobaeys M, De Graef E, et al. Polyphasic characterization of Salmonella Enteritidis isolates on persistently contaminated layer farms during the implementation of a national control program with obligatory vaccination: a longitudinal study. Poult Sci. 2012;91:2727-35. [cited 2015 Dec 1]. Available from: http://www.ncbi.nlm.nih.gov/pubmed/23091125.

32. Kramer A, Schwebke I, Kampf G. How long do nosocomial pathogens persist on inanimate surfaces? A systematic review. BMC Infect Dis. 2006;6: 130. [cited 2015 May 7]. Available from: http://www.biomedcentral.com/ 1471-2334/6/130.

33. Luyckx K, VanWeyenberg S, Dewulf J, Herman L, Zoons J, Vervaet E, et al. On-farm comparisons of different cleaning protocols in broiler houses. Poult Sci. 2015;94:1986-93.

34. Gannon V, Grace D, Atwill ER. Zoonotic waterborne pathogens in livestock and their excreta-interventions. In: Dufour A, Bartram J, Bos R, Gannon V, editors. Animal waste, water quality and human health. London: IWA Publishing; 2012. 